\title{
Fear Factor: Level of Traffic Stress and GPS Assessed Cycling Routes
}

\author{
Katie Crist' ${ }^{1}$, Jasper Schipperijn ${ }^{2}$, Sherry Ryan ${ }^{3}$, Bruce Appleyard ${ }^{3}$, Suneeta Godbole1, \\ Jacqueline Kerr ${ }^{1}$
}

${ }^{1}$ Department of Family Medicine and Public Health, University of California, San Diego, USA

${ }^{2}$ Department of Sports Science and Clinical Biomechanics, University of Southern Denmark, Odense, Denmark

${ }^{3}$ School of Public Affairs, San Diego State University, San Diego, USA

Email: kcrist@eng.ucsd.edu

How to cite this paper: Crist, K., Schipperijn, J., Ryan, S., Appleyard, B., Godbole, S. and Kerr, J. (2019) Fear Factor: Level of Traffic Stress and GPS Assessed Cycling Routes. Journal of Transportation Technologies, 9, 14-30.

https://doi.org/10.4236/jtts.2019.91002

Received: October 10, 2018

Accepted: November 11, 2018

Published: November 14, 2018

Copyright $\odot 2019$ by authors and Scientific Research Publishing Inc. This work is licensed under the Creative Commons Attribution International License (CC BY 4.0).

http://creativecommons.org/licenses/by/4.0/

\begin{abstract}
Background: Cycling currently comprises only $1 \%$ of transport trips in the U.S. despite benefits for air pollution, traffic congestion, and improved public health. Methods: Building upon the Level of Traffic Stress (LTS) methodology, we assessed GPS trip data from utilitarian cyclists to understand route preferences and the level of low stress cycling connection between origins and destinations. GPS data were obtained from adult transport cyclists over multiple days. All bikeable road segments in the network were assigned an LTS score. The shortest paths between each origin and destination along bikeable roadways and along low stress (LTS 1 or 2) routes were calculated. Route trajectories were mapped to the LTS network, and the LTS and distances of observed, the shortest and low stress routes were compared. LTS maps and animations were developed to highlight where low stress connections were lacking. Results: There were 1038 unique cycling trips from 87 participants included in the analysis. An exclusively low stress route did not exist for 51\% of trips. Low stress routes that were possible were, on average, $74 \%$ longer than the shortest possible path and 56\% longer than the observed route. Observed routes were longer and lower stress than the shortest possible route. Conclusions: Results indicate that transport cyclists traveled beyond low stress residential areas and that low stress routes with acceptable detour distances were lacking. Cyclists appeared to weigh both route distance and quality and were willing to trade maximum directness for lower stress. GPS data provide additional information to support planning decisions to increase the impact of infrastructure investments on cycling mode share.
\end{abstract}

\section{Keywords}

Bicycling, Traffic Stress, GPS, Route Choice, LTS 


\section{Introduction}

Increasing active transport has become a key planning strategy to alleviate air pollution, traffic congestion, and improve public health [1] [2] [3] [4] [5]. The Federal Highway Administration (FHWA) set a national goal to increase the proportion of short trips ( $\leq 5$ miles cycling or $\leq 1$ mile walking) taken via walking or cycling to $30 \%$ by 2025 , a reasonable target given that $40 \%$ of trips in the U.S. are within 2 miles of their origin [6] [7]. In San Diego, both the city and county climate action plans include active transport goals to meet California's greenhouse gas (GHG) reduction requirements [8] [9]. Yet, despite these targets to increase mode share, cycling currently only comprises about $1 \%$ of trips locally and nationally [10] [11]. Perceived safety is a significant barrier to transport cycling in the U.S. and abroad [10] [12]-[18]. Evidence suggesting that cyclists select routes to minimize "traffic stress", i.e. the perceived dangers and stressors resulting from proximal interaction with motorized traffic, dates back several decades [19] [20]. Research suggests that even frequent cyclists may extend their journey to ride on low traffic volume roads or facilities that are physically separated from car traffic [12] [21] [22] [23], but distance, slope, traffic volume, safety and intersection features also impact route selection [24]-[30]. In 2006, Roger Geller suggested a system for classifying people into four categories based on their willingness to cycle for transport and their comfort on various types of facilities [31]. A recent national survey, using Geller's categories, classified $4 \%$ of adults as the "Strong and the Fearless" (those who will ride under any conditions), 9\% as "Enthused and Confident" (those who require minimal facilities), $56 \%$ as "Interested but Concerned" (those interested in cycling, but only on comfortable facilities with minimal traffic), and 31\%- "No Way No How" (those who will not ride regardless of conditions) [32]. Studies have shown that perceived safety presents a more significant barrier for those with the least experience in traffic; precisely the group with the greatest potential to adopt cycling for transport [33] [34]. Cycling infrastructure that lowers the actual and perceived risk from traffic will be necessary to attract the large number of potential riders who make up the "Interested but Concerned" group in order to achieve cycling mode share targets.

The Mineta Transportation Institute developed a methodology to classify streets and intersections by the level of traffic stress (LTS) experienced by riders [35] [36]. Planners have adopted LTS as it provides a relatively simple, data driven approach to estimate the comfort and connectivity of a bike network and the population it may serve, using readily available data sources [37] [38]. An advantage of this methodology over other bikeability indices is that the LTS categories correspond to Geller's four types of cyclists, providing planners with a tool to identify how facilities might influence specific segments of the population. LTS categories described acceptability to the following: LTS 1-children, i.e. novice riders with high safety concerns, LTS 2- "Interested but Concerned" adults, LTS 3-the "Enthused and the Confident", and LTS 4-the "Strong and 
the Fearless". The "No Way No How" group was not included as they are unlikely to cycle for transport, regardless of conditions. The Mineta report stipulated that a network is connected at a given stress level when it does not require a detour of more than $25 \%$ over the shortest possible route [35] [39]. This definition of an acceptable detour distance was based, in part, on previous research showing that ninety percent of cycling trips were less than $25 \%$ longer than the shortest route [40]. Based on Dutch cycling design standards, LTS 1 or 2 classifications are considered low stress and acceptable to most adults who would like to cycle but are still concerned about traffic interaction [35] [36] [41] [42]. Thus, a low stress route connecting an origin and destination would be one in which a cyclist can ride exclusively on road segments classified as LTS 1 or 2, without having to increase the distance ridden between those points by more than $25 \%$ over the shortest possible path.

This paper presents a novel analysis of actual cycling routes, assessed by Global Positioning System (GPS), using the LTS methodology. The purpose was to understand the relationship between the quality of cycling networks and utilitarian cycling behavior in San Diego County, as well as the utility of GPS trip data when using LTS as a planning tool. The aims were to 1) develop and visualize a Geographic Information System (GIS) - based LTS classification for the county road network, and 2) compare the distances and LTS of observed, shortest, and low stress cycling routes.

\section{Material and Methods}

\subsection{Participants and Setting}

San Diego County has a population of 3.3 million, including a mix of urban and rural areas, and is geographically the fifth largest county in the U.S. The bike network consists of mainly Class II bike lanes (66\%) and Class III bike routes (18\%) [43]. Cross sectional data from two GPS cycling studies with comparable methods were pooled to create a convenience sample of utilitarian cyclists that included both urban and suburban commuters in the county. The first study ( $\mathrm{N}$ $=40$ ) included adult cyclists recruited through the University of California, San Diego's (UCSD) commuter cycling program. Eligible participants were 18 - 70 year-old university employees who routinely cycled for transportation. A full description of methods can be found elsewhere [44]. The second study $(\mathrm{N}=64)$, included utilitarian cyclists, defined as individuals who regularly cycled for work, school or shopping, 18 years and older who lived and commuted in the City of San Diego [45]. Participants were recruited through the San Diego County Bicycle Coalition's mailing list. Participants in both studies provided informed consent and the Institutional Review Boards from UCSD and San Diego State University SDSU approved all study procedures. Data were collected between November 2010 and July 2011.

\subsection{Data Sources}

Participants were asked to wear a Qstarz 1000x or GT3X+ GPS device (Qstarz 
International Co. Ltd, Taipei, Taiwan) attached to a belt on their hip during waking hours for 3 - 5 days. We included data from participants with at least 1 day of wear as 1 - 2 days is an accepted data collection period for travel behavior surveys [46] [47]. The GPS device was set to capture latitude, longitude and elevation information every 15 seconds. GPS has a median positional error of 2 meters for cycling trips in different environmental conditions, with $86.6 \%$ of points falling within 10 meters of the actual position [48]. Participants charged the GPS every night and received text or email reminders daily. Cycling trips were categorized using the Personal Activity Location Measurement System (PALMS); a validated web-based platform that identifies walking, biking and driving trips using GPS distance, speed and time [44] [49]. Trips were defined by a distance of 100 meters or more, covered at least 25 meters over 1 minute, and were at least 90 seconds long. Pauses of 3 minutes or less were allowed within a trip to accommodate delays like waiting at a traffic light. All data were aggregated to the minute level and each minute was assigned a classification of trip (yes/no) and travel mode [50]. PALMS output points were identified as either start, pause, intermediate or end-points. All round trips with the same origin and destination were manually removed from the data set as this analysis focused on transport trips only. Paper or online surveys captured self-reported demographic variables.

\subsection{LTS Classification and Mapping}

The San Diego Association of Governments (SANDAG) provided GIS data for the San Diego County "all street" network that included all roadways and on and off-street bike paths. We constructed LTS categories using attributes from the street network and based our criteria on LTS applications from multiple sources, including the Mineta report [35] [51] [52] [53]. Information was not available on all of the criteria utilized in the Mineta report (e.g. road/bikeway width and traffic volume data were not available), thus a modified classification was employed using posted speed limit, number of traffic lanes, functional roadway classification, and cycling facility presence and type in each direction of travel (see Figure 1). For intersections, the highest LTS of any segment crossing the intersection was assigned (i.e. an intersection of LTS 1 and LTS 4 roads would receive an LTS 4 rating). LTS 1 or 2 classifications are considered low stress and acceptable to most adults, thus low stress in this paper refers to LTS 1 or 2 [35] [36] [41].

All bikeable road segments, bike paths and intersections in the county were assigned an LTS score in ArcGIS (version 10.5) and maps of the network were created. We excluded road segments where cycling is not permitted (i.e. certain freeways). Three paths between origin and destination (O/D) pairs were compared in this analysis: observed (from GPS), shortest, and low stress (LTS 1 and 2 only) routes. Rather than looking at all possible O/D pairs in the network, we considered the O/D pairs for which we had observed GPS cycling trips in the sample. The start and end-point for each trip were extracted from PALMS. From 


\begin{tabular}{|c|c|c|c|c|c|c|c|c|c|c|c|c|}
\hline \multirow{2}{*}{$\begin{array}{r}\text { Street Type } \\
\text { Posted speed limit (mph) }\end{array}$} & \multicolumn{3}{|c|}{$\begin{array}{l}\text { Class I bike path/ } \\
\text { pedestrian/bikeway }\end{array}$} & \multicolumn{3}{|c|}{$\begin{array}{l}\text { Local street/Alley/ } \\
\text { Cul-de-sac }\end{array}$} & \multicolumn{3}{|c|}{$\begin{array}{c}2 \text { lane collector/rural collector } \\
\text { Local road }\end{array}$} & \multicolumn{3}{|c|}{$\begin{array}{c}2 \text { lane major street } \\
4 \text { lane major road/collector } \\
\text { Primary arterial }\end{array}$} \\
\hline & $<25$ & $25-30$ & $>30$ & $<25$ & $25-30$ & $>30$ & $<25$ & $25-30$ & $>30$ & $<25$ & $25-30$ & $>30$ \\
\hline Off street bike path & LTS 1 & LTS 1 & LTS 1 & LTS 1 & LTS 1 & LTS 1 & LTS 1 & LTS 1 & LTS 1 & LTS 1 & LTS 1 & LTS 1 \\
\hline On street bike lane & LTS 1 & LTS 1 & LTS 1 & LTS 1 & LTS 2 & LTS 2 & LTS 2 & LTS 2 & LTS 3 & LTS 3 & LTS 3 & LTS 4 \\
\hline Signed bike route & LTS 1 & LTS 1 & LTS 1 & LTS 1 & LTS 2 & LTS 3 & LTS 3 & LTS 3 & LTS 4 & LTS 4 & LTS 4 & LTS 4 \\
\hline No bike infrastructure & LTS 1 & LTS 1 & LTS 1 & LTS 1 & LTS 3 & LTS 3 & LTS 3 & LTS 3 & LTS 4 & LTS 4 & LTS 4 & LTS 4 \\
\hline
\end{tabular}

Figure 1. LTS categories by roadway classification, bike facility type and speed limit.

this, we calculated the distance of the shortest possible route between each origin and destination using the ArcGIS Network Analyst OD-matrix function. LTS 3 and 4 segments were removed from the network and the same function was used to compute the shortest low stress path on LTS 1 or 2 roads only. Each route (observed, shortest or low stress), was mapped to the LTS classification layer and overall distance and distance at each LTS level (1 - 4) was calculated and averaged across all trips. An animated cycling trip was created as a dynamic way to visualize the varying stress levels encountered throughout a trip, as opposed to the static map. The LTS linked GPS points were animated using the ArcGIS animation tool.

\subsection{Analyses}

To assess the level of detour required to cycle on low stress routes, we compared the length of low stress routes (LTS 1 or 2 only) to the shortest possible path between each O/D pair, in accordance with the Mekuria et al. methodology. An acceptable level of detour was defined as $\leq 25 \%$ longer than the shortest path [35]. We calculated the percent detour as follows:

$$
\begin{aligned}
& \text { \% Difference in distance over the shortest path }= \\
& {\left[\frac{(\text { Distance on LTS } 1 \text { or } 2 \text { only }- \text { Shortest Path Distance })}{\text { Shortest Path Distance }}\right] \times 100}
\end{aligned}
$$

For example, if the distance of a trip on only LTS 1 or 2 streets was 10 miles and the shortest path was 5 miles, the low stress trip would be $100 \%$ longer [((10 $-5) \div 5)) \times 100=100$ ] than the shortest path. To explore how observed routes compared to shortest and low stress alternate routes, the percent difference in distance was calculated for each in the same manner as described above.

We used the Mann-Whitney U test to compare whether observed and shortest routes had different mean proportion of high stress (LTS 3 or 4) segments. The proportion of LTS percentages was not normally distributed, thus a non-parametric test was appropriate [54] [55]. Low stress routes, by definition, contained only LTS 1 or 2 segments so were not compared.

A Kruskal-Wallis $\mathrm{H}$ test was used to test differences of the average distance of observed, shortest and low stress routes. Low stress only alternate routes existed for only half of all O/D pairs, thus only those routes were included. The Kruskal-Wallis $\mathrm{H}$ test is a nonparametric alternative to test differences between two or more groups [56]. 


\section{Results}

Data from 87 participants living in San Diego County were included in the analysis. There were 1038 unique cycling trips, with an average length of 2.6 miles. The sample was comprised predominantly of white males with an even distribution above and below the approximate median county household income (Table 1). Cyclists averaged 12 trips per person over the study period and approximately $75 \%$ of the sample wore the devices on weekdays only.

\subsection{LTS Visualization}

Stress level was symbolized as follows: LTS $1=$ green, LTS $2=$ yellow, LTS $3=$ orange, and LTS $4=$ red. The freeways and associated ramps, where cycling was not allowed, were not included. A map of the LTS network for San Diego County shows the prevalence of LTS 1 (green) roads in the network, as the majority of the network is comprised of residential, low speed streets (Figure 2).

A more detailed view of a subsection of the region shows an example of the lack of connectivity between urban areas. The arterials and 4 lane connectors, which convey traffic between urban centers, are almost entirely LTS 4 (red). These are crucial connections, especially for commute cycling trips. What results are disconnected "islands" that lack low stress connections between neighborhoods. In the example below, even a cyclist riding a very short distance would be forced to do so on the highest stress roads (Figure 3(a)). When we overlay the GPS route data from the cycling trips in our sample to the same map, we see that the observed routes (blue) indeed follow the high stress connections (Figure 3(b)). This example highlights the lack of direct low stress alternatives connecting east/west or north/south.

Table 1. Sample description.

\begin{tabular}{cc}
\hline Age (years) & \% or Mean (range) \\
\hline $18-34$ & $62.6 \%$ \\
$35-54$ & $31.0 \%$ \\
Over 55 & $14.5 \%$ \\
Male & $74 \%$ \\
White & $87.5 \%$ \\
\hline Household Income & \\
$\leq \$ 70,000$ & $48.4 \%$ \\
$>$ \$70,000 & $50.3 \%$ \\
unreported & $1.3 \%$ \\
\hline Total \# bikeable miles in network & 51,579 \\
Total \# cycling trips & 1038 \\
Weekday only trips & $75 \%$ \\
Mean trip length (miles) & $2.6(0.1,16.2)$ \\
\hline
\end{tabular}




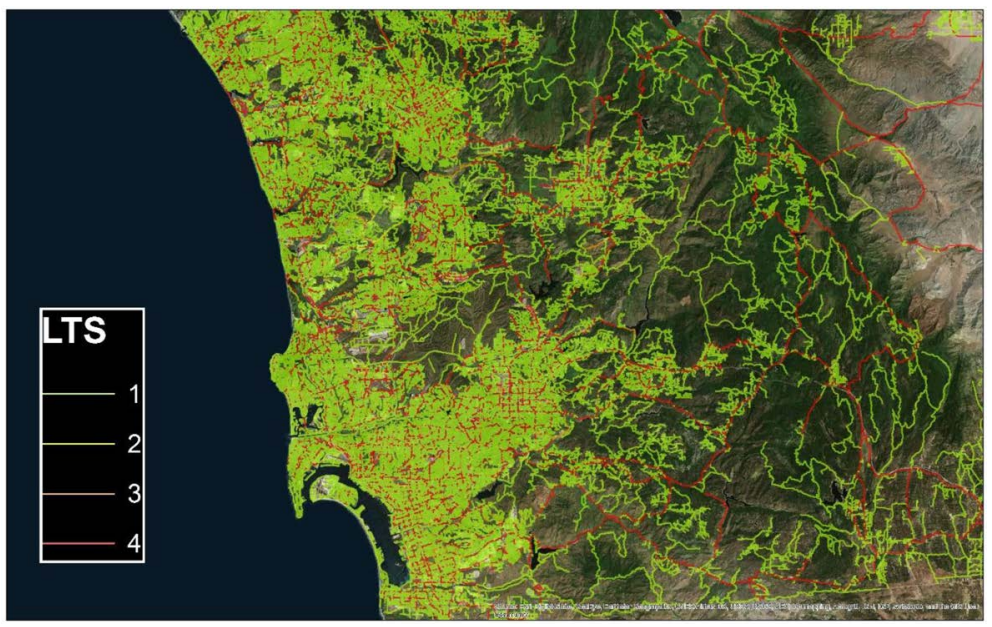

Figure 2. LTS classifications for San Diego county network.

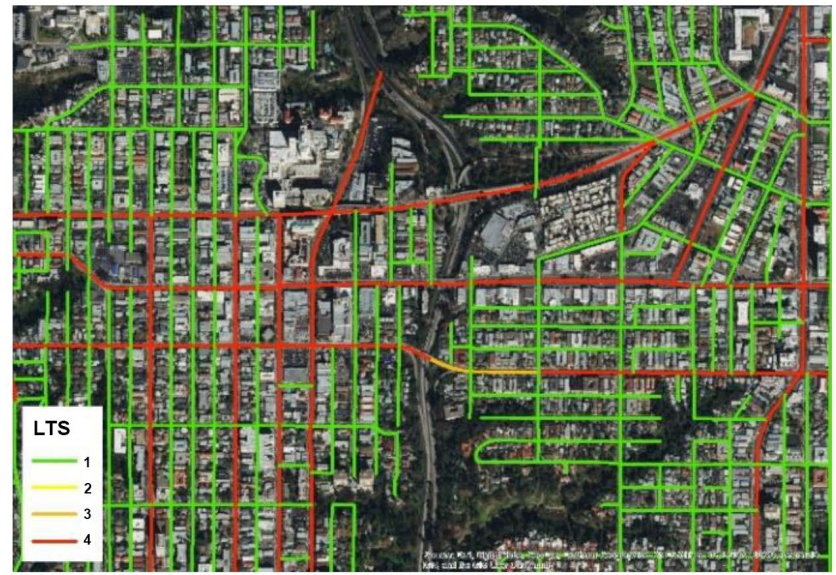

(a)

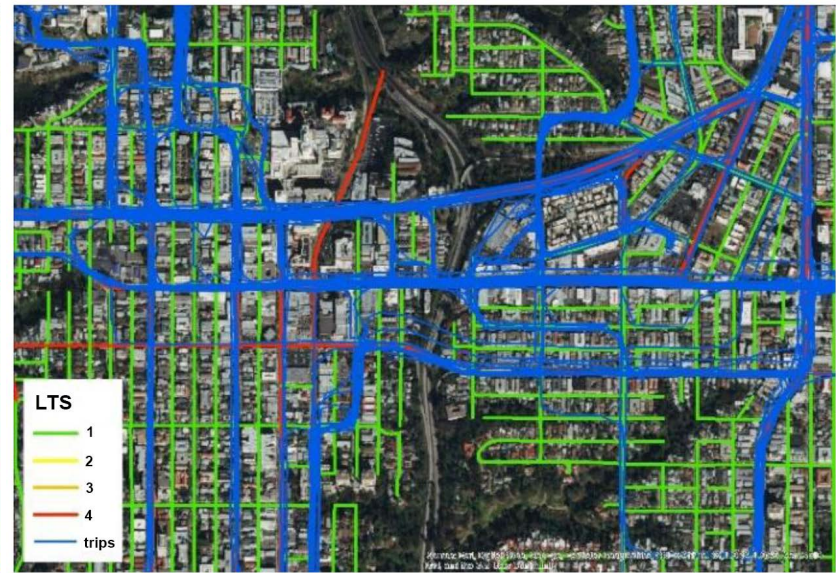

(b)

Figure 3. (a) (left). LTS map; (b) (right). LTS map with GPS cycling routes (blue).

The trip animation (Additional File: Images $\backslash$ Animation $\backslash$ KatieBike_FastCrop. wmv) depicts a cycling trip departing from the Uptown area of San Diego. The points were linked to the LTS road classification and symbolized as follows: Green-LTS 1, Yellow-LTS 2, Orange-LTS 3, Red-LTS 4. You can watch as the cyclist begins the trip on an LTS 4 segment and travels westerly along a main east/west connector (University Avenue) traversing the Uptown community of San Diego. The cyclist then proceeds along a stretch of low stress residential streets through the city's Presidio Park. The cyclist then crosses the Interstate 8 westbound off-ramp that connects to Morena Boulevard, a 4-lane major roadway with high speeds and on-street parking.

\subsection{Description of Cycling Network and Trips by LTS}

Figure 4 presents the percentage of LTS 1 - 4 for bikeable road segments in the San Diego County network compared to observed routes in this sample. In San Diego County, 77\% of bikeable road segments were classified as LTS-1, 1\% LTS 


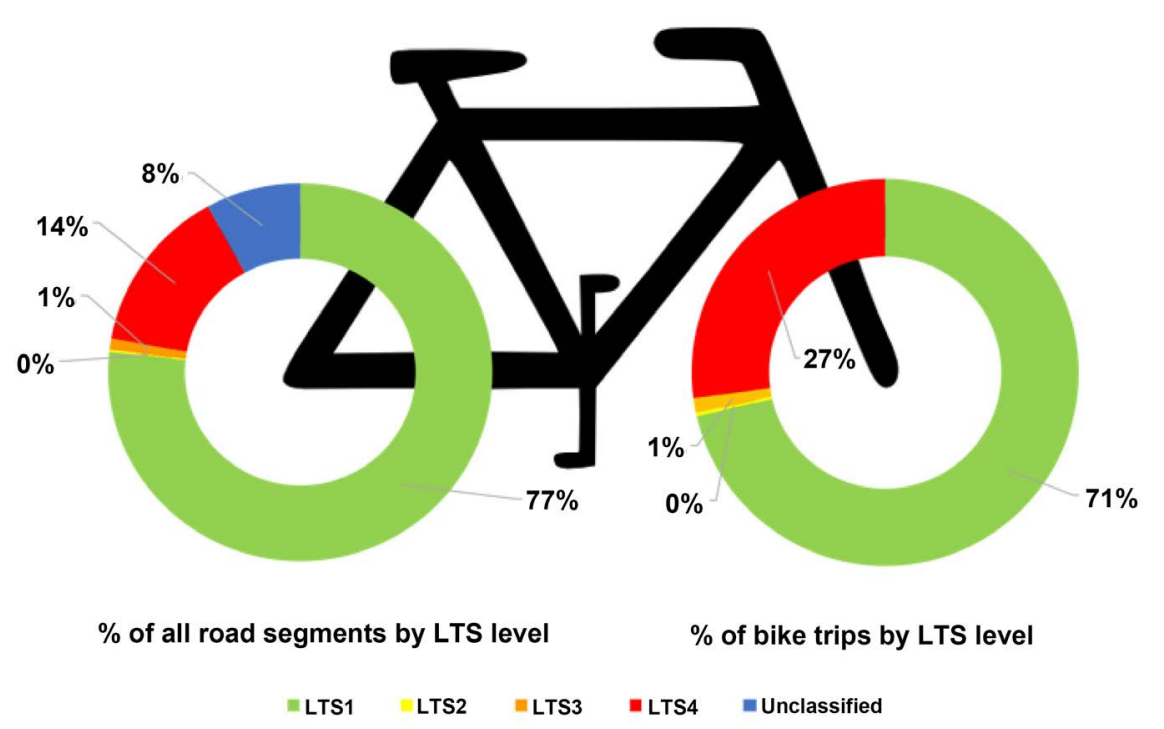

Figure 4. Proportion of San Diego County road network and observed cycling trips by LTS.

2 and 3, and 14\% LTS 4 (8\% not classified because cycling not allowed). In our study, $27 \%$ of observed GPS routes were on the highest stress level, LTS 4, which is nearly double the percentage of LTS 4 road segments available in the county. One percent of trips occurred on LTS 2 and 3, and 71\% at LTS 1 . Only $33 \%$ ( $\mathrm{n}=$ 339) of all trips were entirely on LTS 1 or 2 roads, indicating that that the majority of the sample encountered high stress segments on some part of their trip.

\subsection{Low Stress Connectivity}

To assess the degree to which origins and destinations were connected by low stress routes using the Mekuria et al. definition, LTS 3 and 4 streets were removed and the shortest path between O/D pairs on low stress routes was calculated. Of the 1038 total cycling trips, only $49 \%(n=513)$ had an alternate route where it was possible to travel entirely on low stress (LTS 1 or 2 only) roads. In other words, for half of all trips an exclusively low stress alternate route between O/D pairs did not exist. For the 513 trips that did have a low stress alternate route, $30 \%$ exceeded the acceptable detour distance of $\leq 25 \%$ longer than the shortest path. Thus, overall, only $34 \%$ of trips between O/D pairs in this analysis were possible on low stress routes with an acceptable detour length. Low stress only routes were, on average, $74 \%$ longer than the shortest possible path. To understand how actual cycling routes compared, we similarly computed the difference in distance between low stress and observed routes. LTS 1 and 2 only routes were on average $56 \%$ longer than the observed route.

To explore if cyclists selected the shortest possible route, we compared distances for the three route types. We found a statistically significant difference in distance between the three route types $(\mathrm{p}=0.001)$. However, pairwise comparisons showed that only the low stress $(3144 \mathrm{~m})$ and shortest $(1832 \mathrm{~m})$ routes were 
significantly different $(\mathrm{p}<0.0001)$. Observed trips $(2047 \mathrm{~m})$ were, on average, $15 \%$ longer than the shortest path, but this difference was not statistically significant $(\mathrm{p}=0.306)$. The Mann-Whitney $U$ test results revealed that the shortest route had a significantly higher proportion of high stress segments compared to observed routes $(48 \%$ vs $30 \%, \mathrm{p}<0.0001)$. Figure 5(a) and Figure 5(b) present the LTS and distances for actual cycling routes and the low stress and shortest path alternatives.

\section{Discussion}

This study presents a novel approach to evaluating transport cycling using GPS traces of cycling routes in conjunction with the LTS methodology. We used observed GPS trip data from utilitarian cyclists to assess preference for direct or low stress routes and the degree of connectivity between $\mathrm{O} / \mathrm{D}$ pairs of recorded GPS trips. The majority of the San Diego road network was classified as LTS 1 or 2 , due to the prevalence of wide, low speed residential streets in both urban and suburban areas. In contrast, GPS trip data revealed that roughly one-third of actual cycling trips occurred on the highest stress (LTS 4) road segments. We compared the distance and LTS of observed routes to shortest and low stress alternatives to further explore route selection. A low stress (LTS 1 or 2) cycling route did not exist for more than half of trips in this sample. Those trips that did have a low stress alternate route were $74 \%$ longer than the shortest possible path and 56\% longer than observed routes, far exceeding acceptable detour distances. Observed routes were slightly longer than the shortest path but had a lower proportion of high stress (LTS 4) segments. The difference in distance between actual and shortest routes in this study was greater than reported by others [40] [57] [58] [59], however was not statistically significant. Findings lend support to previous studies that have shown cyclists prefer to travel on lower stress roads, but also value directness [25] [40] [58] [60]. In our sample, cyclists may have chosen slightly longer routes in order to travel on lower stress roads, but were unwilling to travel the excessive distances required to travel on exclusively low stress routes, if available. Transport cycling in San Diego, especially for commuting, requires use of arterials and large connector streets that provide critical links between residential areas and destinations. San Diego has numerous canyons through the urban core, which means that bridges are often necessary connections between neighborhoods. LTS maps highlighted that these connecting roads and bridges were most often classified as LTS 3 and 4. This may have contributed to the excessive detour distances required to take low stress alternate routes.

The current study is not without limitations. Though a small convenience sample, there were more than 1000 transport cycling trips analyzed, with GPS information collected every 15 seconds. Recruitment focused on utilitarian cyclists who likely have more cycling experience, thus it is possible that this inflated the proportion of trips observed on LTS 4 . The connectivity analysis, however, demonstrated that lower stress options were generally not available between 


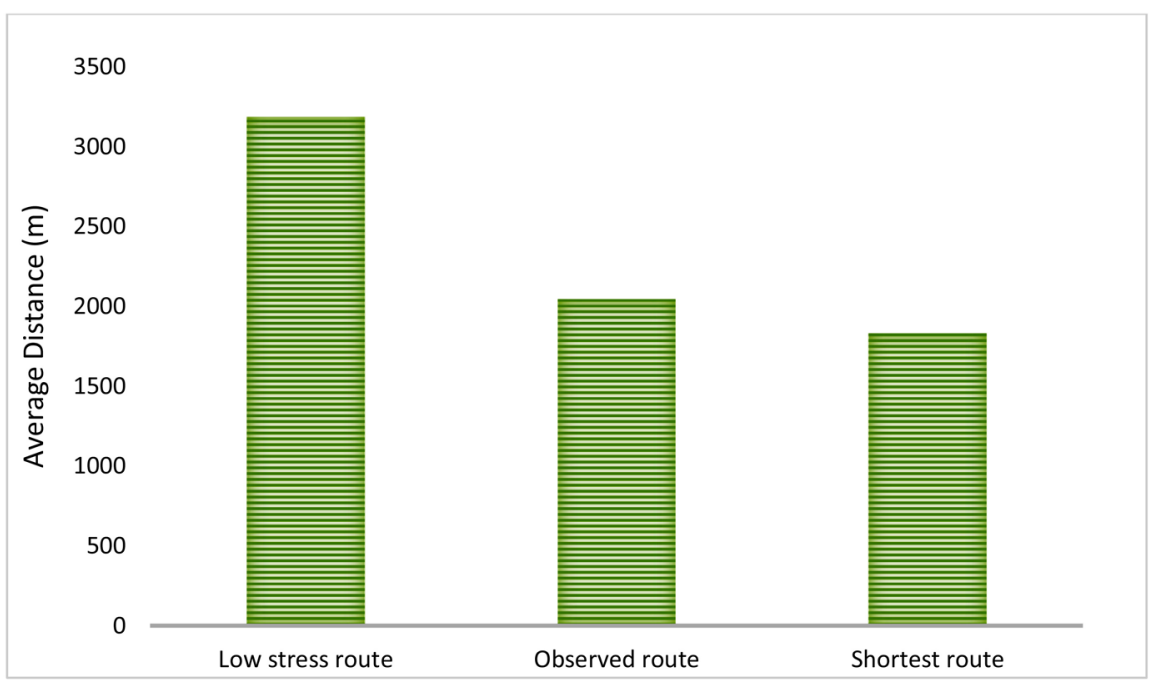

(a)

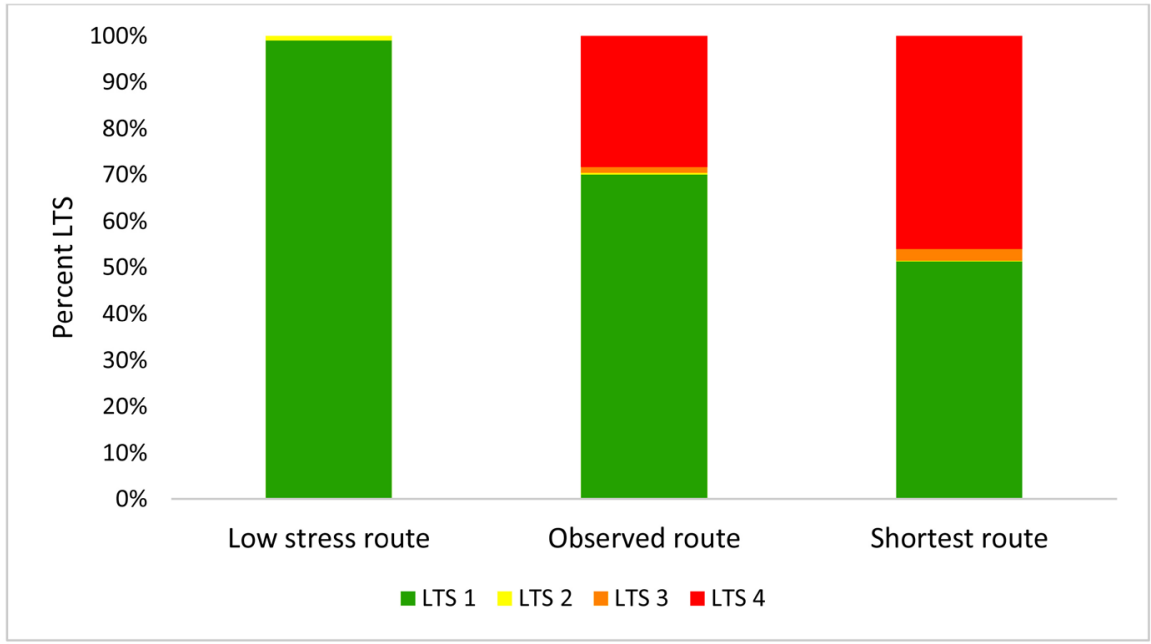

(b)

Figure 5. (a) Distance of low stress, observed and shortest routes; ${ }^{\star}$ Significant difference in distance between low stress and shortest route only ( $<<0.0001)$; (b) LTS of low stress, observed and shortest routes. ${ }^{*}$ Significant difference in LTS levels between observed and shortest route $(\mathrm{p}<0.0001)$.

origins and destinations without an unreasonable detour. We don't know the proportion of commute versus other types of transport trips, which may have impacted route selection as reported by Broach, Dill and Gliebe [21]. Multi-year manual counts conducted by researchers working with two of this study's authors, Ryan and Appleyard, have shown a large proportion (about $75 \%$ ) of bicycle riders in San Diego are male [61]. Therefore, our study sample may present a consistent profile of the current cycling populous in this region, though our knowledge of representativeness of this sample is limited. We did not collect information on perceived or actual stress experienced by riders, though studies have found a relationship between LTS and reported comfort level [62]. Other predictors of route choice, including topography, traffic signals, and green sur- 
roundings, were not assessed and may have contributed to the findings [21] [23] [26] [40] [63] [64] [65] [66]. We utilized the available data to create LTS classifications but did not have access to all variables used in the Mineta methodology, most significantly traffic volume [35]. We employed functional roadway classifications instead, which correlates with traffic volume. These data limitations would similarly be faced by many planning agencies and the included variables captured attributes of the network commonly used in LTS analyses [36]. This study analyzed cross-sectional route data, which does not allow us to evaluate the causal relationship between LTS and route selection.

To our knowledge, this paper is the first to utilize GPS data to analyze utilitarian cycling routes in relation to the LTS classification scheme. Blanc and Figliozzi found that cycling facility type and self-reported sources of stress, particularly vehicle traffic, had a negative impact on comfort ratings of the route (Blanc and Figliozzi, 2016). The route comfort ratings approximated LTS levels (i.e. "Bad" was for confident riders only), however they were self-reported by participants rather than created using GIS data. Wang et al. examined whether LTS predicted cycling trips reported in the Oregon Household Activities Survey [67]. They showed a correlation between the availability of low stress routes between home, school and work locations and cycling mode choice. However, GPS data were not available to determine whether participants actually utilized low stress routes over alternate paths. Bikeability indices that include factors similar to the LTS infrastructure and traffic volume criteria have been shown to be associated with cycling behavior [64] [65]. A benefit of the LTS methodology over other indices is that the classification levels relate to specific types of cyclists, which may improve planning efforts aimed at increasing cycling mode share.

\section{Conclusions}

Roger Geller stated, "No person should have to be 'brave' to ride a bicycle", yet that is the scenario faced by transport cyclists in many U.S. cities, including San Diego. Despite the majority of county roadways being classified as low stress, almost $70 \%$ of utilitarian trips included high stress (LTS 4) segments. The network in San Diego County was suitable for "Strong and Fearless" cyclists, as low stress connections between residential areas either did not exist or required unacceptable detour distances. Slight detours may be tolerated; however, it is not likely that cyclists will use routes that are nearly double in distance over the most direct route. The more likely impact of a lack of low stress infrastructure and excessive detour is that the "Interested but Concerned" segment of the population will choose instead not to cycle. Large increases in mode share have been achieved in cities that have invested in pro-cycling facilities, programs and policies [10]. Results from a five-city project assessing cycle tracks, lanes that are protected from traffic by some types of physical barrier, found increased ridership, safety and comfort levels. Importantly, 10\% of riders reported switching from another transport mode and a quarter said they had increased their cycling 
because of the new infrastructure. Another $25 \%$ shifted from other routes to utilize the protected route [68].

Future studies should include longitudinal assessment to evaluate the impact of infrastructure changes that reduce LTS on ridership and route selection. $\mathrm{Nu}$ merous smartphone apps could be used to collect cycling trip data. Strava is one of the most used apps and Strava Metro, the commercial arm of the company, has sold cycling data to several planning agencies [69]. However, these data sources should be interpreted with caution as users may represent a specific type of cyclist. For example, the average trip distance for Strava users in the U.S. in 2016 was 21.2 miles, compared to the mean distance of 2.6 miles in this sample [70]. Data from GPS enabled bike share programs may provide larger data sets about where cyclists actually ride in order to inform infrastructure investments. Our previous research found that animations, like the one presented here, were of interest to local planners who thought they could aid communication with community members and elected officials [71]. Cyclists in this study appeared to weigh both route distance and quality and were willing to trade maximum directness for lower stress. Future studies should include other roadway attributes to better understand route selection. Smartphones linked to body sensors, like heart rate monitors, could facilitate understanding of the relationship between LTS and objective measures of stress. Research should focus on different segments of the population, like women, older adults and those who do not currently cycle, in order to better understand the facilitators of mode shift [72]. As Kent and Karner pointed out in a recent paper, LTS should be used carefully to ensure that investments in infrastructure to lower traffic stress are done equitably and benefit disadvantaged communities [73]. In general, the incorporation of GPS route data could aid planners in understanding where cyclists ride and prioritizing improvements to the network that is most likely to shift transport mode from vehicles to cycling.

\section{Funding}

This work was supported by the National Cancer Institute at the National Institutes of Health (Grants U01CA130771).

\section{Acknowledgements}

We would like to acknowledge SANDAG modeling team for the provision of the road network data and Eduardo Cordova for assistance with the shortest path analysis.

\section{Conflicts of Interest}

The authors declare no conflicts of interest regarding the publication of this paper.

\section{References}

[1] Oja, P., Titze, S., Bauman, A., de Geus, B., Krenn, P., Reger-Nash, B. and Kohlberg- 
er, T. (2011) Health Benefits of Cycling: A Systematic Review. Scandinavian Journal of Medicine \& Science in Sports, 21, 496-509. https://doi.org/10.1111/j.1600-0838.2011.01299.x

[2] World Health Organization (WHO) (2018) Global Action Plan on Physical Activity 2018-2030. World Health Organization, Geneva.

[3] Maizlish, N., Woodcock, J., Co, S., Ostro, B., Fanai, A., Imeche, C. and Fairley, D. (2013) Health Cobenefits and Transportation-Related Reductions in Greenhouse Gas Emissions in the San Francisco Bay Area. American Journal of Public Health, 103, 703-709. https://doi.org/10.2105/AJPH.2012.300939

[4] Giles-Corti, B., Vernez-Moudon, A., Reis, R., Turrell, G., Dannenberg, A.L., Badland, H., Foster, S., Lowe, M., Sallis, J.F., Stevenson, M. and Owen, N. (2016) City Planning and Population Health: A Global Challenge. Lancet, 388, 2912-2924.

https://doi.org/10.1016/S0140-6736(16)30066-6

[5] Global Advocacy for Physical Activity (GAPA) the Advocacy Council of the International Society for Physical Activity and Health (ISPAH) (2011) NCD Prevention: Investments that Work for Physical Activity.

[6] FHWA (2016) Strategic Agenda for Pedestrian and Bicycle Transportation. FHWA, Washington DC.

[7] FHWA (2011) Summary of Travel Trends: 2009 National Household Travel Survey. FHWA, Washington DC.

[8] City of San Diego (2015) Climate Action Plan. San Diego.

[9] County of San Diego (2018) Climate Action Plan. San Diego.

[10] Pucher, J., Buehler, R. and Seinen, M. (2011) Bicycling Renaissance in North America? An Update and Re-Appraisal of Cycling Trends and Policies. Transportation Research Part A: Policy and Practice, 45, 451-475. https://doi.org/10.1016/j.tra.2011.03.001

[11] U.S. Census Bureau (2015) 2015 American Community Survey. https://factfinder.census.gov/faces/tableservices/jsf/pages/productview.xhtml?pid=A CS_16_5YR_B08301\&prodType=table

[12] Heinen, E., Van Wee, B., Maat, K. and Ttrv, F. (2010) Commuting by Bicycle: An Overview of the Literature. Transport Reviews, 30, 59-96. https://doi.org/10.1080/01441640903187001

[13] Fowler, S.L., Berrigan, D. and Pollack, K.M. (2017) Perceived Barriers to Bicycling in an Urban U.S. Environment. Journal of Transport \& Health, 6, 474-480. https://doi.org/10.1016/j.jth.2017.04.003

[14] Handy, S.L. and Xing, Y. (2011) Factors Correlated with Bicycle Commuting: A Study in Six Small U.S. Cities. International Journal of Sustainable Transportation, 5, 91-110. https://doi.org/10.1080/15568310903514789

[15] Winters, M., Davidson, G., Kao, D. and Teschke, K. (2011) Motivators and Deterrents of Bicycling: Comparing Influences on Decisions to Ride. Transportation (AMST), 38, 153-168. https://doi.org/10.1007/s11116-010-9284-y

[16] Heesch, K.C., Sahlqvist, S. and Garrard, J. (2011) Brief Original Report Cyclists' Experiences of Harassment from Motorists: Findings from a Survey of Cyclists in Queensland, Australia. Preventive Medicine, 53, 417-420. https://doi.org/10.1016/j.ypmed.2011.09.015

[17] Chataway, E.S., Kaplan, S., Nielsen, T.A.S. and Prato, C.G. (2014) Safety Perceptions and Reported Behavior Related to Cycling in Mixed Traffic: A Comparison between Brisbane and Copenhagen. Transportation Research Part F: Traffic Psychology and 
Behaviour, 23, 32-43. https://doi.org/10.1016/j.trf.2013.12.021

[18] Mertens, L., Compernolle, S., Gheysen, F., Deforche, B., Brug, J., Mackenbach, J.D., Lakerveld, J., Oppert, J.-M., Feuillet, T., Glonti, K., Bárdos, H. and De Bourdeaudhuij, I. (2016) Perceived Environmental Correlates of Cycling for Transport among Adults in Five Regions of Europe. Obesity Reviews, 17, 53-61. https://doi.org/10.1111/obr.12379

[19] Sorton, A. and Walsh, T. (1994) Bicycle Stress Level as a Tool to Evaluate Urban and Suburban Bicycle Compatibility. Transportation Research Record 1438, Washington DC.

[20] Davis, W.J. (1987) Bicycle Safety Evaluation. Auburn University, Chattanooga.

[21] Broach, J., Dill, J. and Gliebe, J. (2012) Where Do Cyclists Ride? A Route Choice Model Developed with Revealed Preference GPS Data. Transportation Research Part A: Policy and Practice, 46, 1730-1740. https://doi.org/10.1016/j.tra.2012.07.005

[22] Buehler, R. and Dill, J. (2015) Bikeway Networks: A Review of Effects on Cycling. Transport Reviews, 36, 9-27. https://doi.org/10.1080/01441647.2015.1069908

[23] Vedel, S.E., Jacobsen, J.B. and Skov-Petersen, H. (2017) Bicyclists' Preferences for Route Characteristics and Crowding in Copenhagen-A Choice Experiment Study of Commuters. Transportation Research Part A: Policy and Practice, 100, 53-64. https://doi.org/10.1016/j.tra.2017.04.006

[24] Harvey, F., Krizek, K.J. and Collins, R. (2008) Using GPS Data to Assess Bicycle Commuter Route C Hoice. Transportation Research Board 87 th Annual Meeting, Washington DC, 13-17 January 2008.

[25] Broach, J., Dill, J. and Gliebe, J. (2012) Where Do Cyclists Ride? A Route Choice Model Developed with Revealed Preference GPS Data. Transportation Research Part A: Policy and Practice, 46, 1730-1740. https://doi.org/10.1016/j.tra.2012.07.005

[26] Menghini, G., Carrasco, N., Schüssler, N. and Axhausen, K.W. (2010) Route Choice of Cyclists in Zurich. Transportation Research Part A: Policy and Practice, 44, 754-765. https://doi.org/10.1016/j.tra.2010.07.008

[27] Casello, J., Nour, A., Rewa, K. and Hill, J. (2011) Analysis of Stated-Preference and GPS Data for Bicycle Travel Forecasting. Transportation Research Board 90 th Annual Meeting Location, Washington DC, 23-27 January 2011.

[28] Casello, J. and Usyukov, V. (2014) Modeling Cyclists' Route Choice Based on GPS Data. Transportation Research Record Journal of the Transportation Research Board, 2430, 155-161. https://doi.org/10.3141/2430-16

[29] Beatriz Pereira Segadilha, A. and da Penha Sanches, S. (2014) Analysis of Bicycle Commuter Routes Using GPSs and GIS. Procedia-Social and Behavioral Sciences, 162, 198-207. https://doi.org/10.1016/j.sbspro.2014.12.200

[30] Hood, J., Sall, E. and Charlton, B. (2011) A GPS-Based Bicycle Route Choice Model for San Francisco, California. Transportation Letters. The International Journal of Transportation Research, 3, 63-75. https://doi.org/10.3328/TL.2011.03.01.63-75

[31] Geller, R. (2006) Four Types of Cyclists. Portland Bureau of Transportation, Portland.

[32] Dill, J. and McNeil, N. (2016) Revisiting the Four Types of Cyclists: Findings from a National Survey. Transportation Research Record Journal of the Transportation Research Board, 2587, 17. https://doi.org/10.3141/2587-11

[33] Hunt, J.D., Abraham, A.J.E., Abraham, J.E., Hunt, J.D. and Abraham, A.E.J.E. (2007) Influences on Bicycle Use. Transportation (AMST), 34, 453-470. 
https://doi.org/10.1007/s11116-006-9109-1

[34] O’Connor, J.P. and Brown, T.D. (2010) Riding with the Sharks: Serious Leisure Cyclist's Perceptions of Sharing the Road with Motorists. Journal of Science and Medicine in Sport, 13, 53-58. https://doi.org/10.1016/j.jsams.2008.11.003

[35] Mekuria, M.C., Furth, P.G. and Nixon, H. (2012) Low-Stress Bicycling and Network Connectivity. Mineta Transportation Institute, San Jose.

[36] Mekuria, M., Appleyard, B. and Nixon, H. (2017) Improving Livability Using Green and Active Modes: A Traffic Stress Level Analysis of Transit, Bicycle, and Pedestrian Access and Mobility. Mineta Transportation Institute, San Jose.

[37] Alta Planning + Design (2018) Level of Traffic Stress-What It Means for Building Better Bike Networks.

https://blog.altaplanning.com/level-of-traffic-stress-what-it-means-for-building-bet ter-bike-networks-c4af9800b4ee

[38] PeopleForBikes (2018) Bike Network Analysis. https://bna.peopleforbikes.org/\#/methodology

[39] Dill, McNeil and Nathan (2016) TRR 2587. Transportation Research Record Journal of the Transportation Research Board, 2587, 90-99.

[40] Winters, M., Teschke, K., Grant, M., Setton, E.M., Brauer, M., Winters, M., Teschke, K. and Brauer, M. (2010) How Far Out of the Way Will We Travel? Built Environment Influences on Route Selection for Bicycle and Car Travel. Transportation Research Record Journal of the Transportation Research Board, 2190, 1-10. https://doi.org/10.3141/2190-01

[41] Dill, J. and McNeil, N. (2013) Four Types of Cyclists? Transportation Research Record Journal of the Transportation Research Board, 2387, 129-138. https://doi.org/10.3141/2387-15

[42] Furth, P.G., Mekuria, M.C. and Nixon, H. (2016) Network Connectivity for Low-Stress Bicycling. Transportation Research Record Journal of the Transportation Research Board, 2587, 41-49. https://doi.org/10.3141/2587-06

[43] SANDAG (2010) San Diego Regional Bike Plan 2010. https://www.google.com/search?q=San+Diego+Regional+Bike+Plan+2010\&rlz=1C 1CHZL_enUS739US739\&oq=San+Diego+Regional + Bike + Plan $+2010 \& a q s=$ chrome. $.69 \mathrm{i} 57 \mathrm{j} 69 \mathrm{i} 64.2236 \mathrm{j} 0 \mathrm{j} 7$ \&sourceid $=$ chrome\&ie $=\mathrm{UTF}-8$

[44] Kerr, J., Marshall, S., Godbole, S. and Chen, J. (2013) Using the SenseCam to Improve Classifications of Sedentary Behavior in Free-Living Settings. American Journal of Preventive Medicine, 44, 290-296. https://doi.org/10.1016/j.amepre.2012.11.004

[45] Haislip, L. (2011) An Examination of Utilitarian Bicycle Trip Route Choice Preference in San Diego. San Diego State University, San Diego.

[46] Evenson, K.R., Neelon, B., Ball, S.C., Vaughn, A. and Ward, D.S. (2008) Validity and Reliability of a School Travel Survey. Journal of Physical Activity and Health, 5, S1-15. https://doi.org/10.1123/jpah.5.s1.s1

[47] Petrunoff, N.A., Xu, H., Rissel, C., Wen, L.M. and van der Ploeg, H.P. (2013) Measuring Workplace Travel Behaviour: Validity and Reliability of Survey Questions. Journal of Environmental and Public Health, 2013, Article ID: 423035. https://doi.org/10.1155/2013/423035

[48] Schipperijn, J., Kerr, J., Duncan, S., Madsen, T., Klinker, C.D. and Troelsen, J. (2014) Dynamic Accuracy of GPS Receivers for Use in Health Research: A Novel Method to Assess GPS Accuracy in Real-World Settings. Frontiers in Public Health, 


\section{2, 21. https://doi.org/10.3389/fpubh.2014.00021}

[49] Carlson, A., Jankowska, M.M., Meseck, K., Godbole, S., Natarajan, L., Raab, F., Demchak, B., Patrick, K. and Kerr, J. (2015) Validity of PALMS GPS Scoring of Active and Passive Travel Compared with SenseCam. Medicine \& Science in Sports \& Exercise, 47, 662-667. https://doi.org/10.1249/MSS.0000000000000446

[50] UCSD-PALMS-Project-Home. http://ucsd-palms-project.wikispaces.com/

[51] Montgomery County Bicycle Master Plan (2018) Appendix D Level of Traffic Stress Methodology. http://www.mcatlas.org/bikestress/

[52] Ryan, C. (2015) Pedestrian and Bicycle Performance Measure Evaluation. Prepared for City of San Diego, San Diego.

[53] People for Bikes (2018) Bike Network Analysis Methodology. https://bna.peopleforbikes.org/\#/methodology

[54] Hart, A. (2001) Mann-Whitney Test Is Not Just a Test of Medians: Differences in Spread Can Be Important. BMJ, 323, 391-393. https://doi.org/10.1136/bmj.323.7309.391

[55] Mann, H.B. and Whitney, D.R. (1947) On a Test of Whether One of Two Random Variables Is Stochastically Larger than the Other. Annals of Mathematical Statistics, 18, 50-60. https://doi.org/10.1214/aoms/1177730491

[56] Kruskal, W.H. and Wallis, W.A. (1952) Use of Ranks in One-Criterion Variance Analysis. Journal of the American Statistical Association, 47, 583-621. https://doi.org/10.1080/01621459.1952.10483441

[57] Dill, J. and Gliebe, J. (2008) Understanding and Measuring Bicycling Behavior: A Focus on Travel Time and Route Choice Final Report. Oregon Transportation Research and Education Consortium (OTREC), Portland. https://doi.org/10.15760/trec.151

[58] Krenn, P., Oja, P. and Titze, S. (2014) Route Choices of Transport Bicyclists: A Comparison of Actually Used and Shortest Routes. International Journal of Behavioral Nutrition and Physical Activity, 11, 31. https://doi.org/10.1186/1479-5868-11-31

[59] Howard, C. and Burns, E. (2001) Cycling to Work in Phoenix: Route Choice, Travel Behavior, and Commuter Characteristics. Transportation Research Record Journal of the Transportation Research Board, 1773, 39-46. https://doi.org/10.3141/1773-05

[60] Skov-Petersen, H., Barkow, B., Lundhede, T. and Jacobsen, J.B. (2018) How Do Cyclists Make Their Way?-A GPS-Based Revealed Preference Study in Copenhagen. International Journal of Geographical Information Science, 32, 1469-1484. https://doi.org/10.1080/13658816.2018.1436713

[61] Ryan, S., Appleyard, B., Schroeder, C. and Prescott, A. (2014) Estimating Daily Bicycle Volumes Using Manual Short Duration and Automated Continuous Counts. Presented at 93rd Annual Meeting of the Transportation Research Board, Washington DC, 12-16 January 2014.

[62] Blanc, B. and Figliozzi, M. (2016) Modeling the Impacts of Facility Type, Trip Characteristics, and Trip Stressors on Cyclists' Comfort Levels Utilizing Crowdsourced Data. Transportation Research Record Journal of the Transportation Research Board, 2587, 100-108. https://doi.org/10.3141/2587-12

[63] Krenn, P.J., Oja, P. and Titze, S. (2014) Route Choices of Transport Bicyclists: A Comparison of Actually Used and Shortest Routes. International Journal of Behavioral Nutrition and Physical Activity, 11, 1-7. 
https://doi.org/10.1186/1479-5868-11-31

[64] Krenn, P.J., Oja, P., Titze, S. and Krenn, P.J. (2015) Development of a Bikeability Index to Assess the Bicycle-Friendliness of Urban Environments. The Open Civil Engineering Journal, 5, 451-451. https://doi.org/10.4236/ojce.2015.54045

[65] Winters, M., Brauer, M., Setton, E.M., Teschke, K., Winters, M., Brauer, M., Setton, E.M. and Teschke, K. (2013) Mapping Bikeability: A Spatial Tool to Support Sustainable Travel. Environment and Planning B: Urban Analytics and City Science, 40, 865-883. https://doi.org/10.1068/b38185

[66] Nielsen, T.A.S., Olafsson, A.S., Carstensen, T.A. and Skov-Petersen, H. (2013) Environmental Correlates of Cycling: Evaluating Urban Form and Location Effects Based on Danish Micro-Data. Transportation Research Part D: Transport and Environment, 22, 40-44. https://doi.org/10.1016/j.trd.2013.02.017

[67] Wang, H., Vogt, R. and Palm, M. (2015) Geospatial Analysis of Bicycle Network "Level of Traffic Stress", Bicycle Mode Choice Behaviour and Bicycle Crashes for Risk Factor Identification. Pacific Northwest Transportation Consortium (PacTrans), Seattle, 46.

[68] Monsere, C., Dill, J., McNeil, N., Clifton, K., Foster, N. and Goddard, T. (2014) Lessons from the Green Lanes: Evaluating Protected Bike Lanes in the U.S. National Institute for Transportation and Communities, NITC-RR-58, 1-179.

[69] Romanillos, G., Zaltz Austwick, M., Ettema, D. and De Kruijf, J. (2016) Big Data and Cycling. Transport Reviews, 36, 114-133.

https://doi.org/10.1080/01441647.2015.1084067

[70] Strava End of Year Insights (2016) https://www.dropbox.com/sh/bd53sbohy86rlbf/AACI6dnxvf769RZM6Fc_H4Ata?dl $=0$ \&preview $=$ Strava + End + of + Year + Insights.pdf

[71] Crist, K., Bolling, K., Schipperijn, J., Hurst, S., Takemoto, M., Sallis, J.F., Badland, H. and Kerr, J. (2017) Collaboration between Physical Activity Researchers and Transport Planners: A Qualitative Study of Attitudes to Data Driven Approaches. Journal of Transport \& Health, 8, 157-168. https://doi.org/10.1016/j.jth.2017.11.142

[72] Aldred, R., Elliott, B., Woodcock, J. and Goodman, A. (2017) Cycling Provision Separated from Motor Traffic: A Systematic Review Exploring Whether Stated Preferences Vary by Gender and Age. Transport Reviews, 37, 29-55. https://doi.org/10.1080/01441647.2016.1200156

[73] Kent, M. and Karner, A. (2018) Prioritizing Low-Stress and Equitable Bicycle Networks Using Neighborhood-Based Accessibility Measures. International Journal of Sustainable Transportation, 1-11. 